\title{
THE SURGICAL MANAGEMENT OF LATE TUBERCULOUS SPACE INFECTIONS AFTER PLOMBAGE
}

\author{
BY \\ A. M. MACARTHUR \\ From St. Helier Hospital, Carshalton, Surrey \\ (RECEIVED FOR PUBLICATION OCTOBER 9, 1957)
}

The introduction of unabsorbable foreign materials into the tissues is liable to be followed by late infection and their extrusion. This has been found particularly to be the case when such materials have been used to maintain surgical collapse of a tuberculous lung. The early results of extrapleural oleothorax and paraffin wax plombage were satisfactory and gave a high proportion of closed cavities without deformity (McIndoe, Steele, and Alexander, 1939). With the passage of time, however, the increasing number of cases developing a late tuberculous empyema led to these materials being abandoned. The advent of plastics and their application in surgery brought about a revival in the plombage type of operation (Wilson, 1948). This revival came at a time when thoracoplasty, although a proved and widely used operation, was, in some quarters, falling under criticism because of the deformity and loss of respiratory function associated with the procedure. Pulmonary resection had not then been established as a standard method of treatment, and it was during this period in the evolution of the surgery of tuberculosis that plombage with plastic materials had a vogue. Apart from its advantages as a cosmetic, one-stage procedure, one of the most attractive features of plombage was its applicability to the poor risk patient who had bilateral disease and reduced respiratory reserve. Early experiences with lucite spheres used to maintain collapse after extrapleural pneumonolysis were not satisfactory (Trent, Moody, and Hiatt, 1949). But the operation introduced by Lucas and Cleland (1950), which can be described as an extrafascial, extraperiosteal plombage, in which the rib cage is left intact and a layer of intercostal tissues maintained between the foreign bodies and the lung, gave excellent results in the early stages of its trial. As these cases are followed up it has become apparent that the plastic materials are heir to the same late complication as their predecessors. Reported series show an incidence of about $5 \%$ late space infections in the first five years after operation (Jackson and McCann, 1956; Cleland, 1956). Inada, Satô, Kishimotô, and Tanabe (1954) in Japan found this complication in one third of 106 operations. In the course of time it is likely that a high proportion of plastic plombs will become infected and Cleland (1956) has expressed his disquiet on this point.

If the development of a tuberculous space infection is recognized early and its treatment instituted promptly it is not serious. Unfortunately, the onset of infection is usually insidious and if the early signs are overlooked, the complication can be important. It is the object of this paper to draw attention to the ways in which this complication may present and to suggest the surgical measures necessary to deal with it. Twenty-two patients who developed space infections have been studied. The original operations were done by five different surgeons, but they were all of the extrafascial, extraperiosteal type. The foreign material was in every case either polythene or lucite. Although it has been found (Desforges, Gibbons, and Strieder, 1954) that tubercle bacilli can be recovered from the space shortly after operation, clinical evidence of an infected plomb takes longer, usually about three years, to appear. The presenting features are variable and can be grouped as follows:

(a) The infection may present as a vague illness, often regarded as influenza by the patient, associated with general malaise, pain at the operation site, and a low-grade pyrexia. An increase in the erythrocyte sedimentation rate is a frequent finding and may be the only sign (Jackson and McCann, 1956). In such a case there may be no local or radiographic change, but aspiration of the space reveals the presence of pus. Only a few millilitres of pus may be obtainable because of loculation.

(b) There may be radiographic changes only. These include thinning of the ribs or actual painless fracture. That the appearances may precede the clinical signs of fluid by a long period is demonstrated by the following case. 
A man of 35 underwent a right lucite plombage in June, 1950; two years later serial radiographs revealed progressive erosion and ultimate fracture of the ribs overlying the pack. He remained well and working for a further two years until the fluid ruptured into the lung and formed a fistula.

In all extraperiosteal operations there is a certain amount of rib deformity and sclerosis, best seen in radiographs in the axillary region; but where the changes are progressive the possibility of a slowly developing empyema should be borne in mind. If hollow spheres have been used the development of fluid may be indicated by the appearance of fluid levels inside the spheres or changes in levels already present. With the solid plombage a clue is sometimes given by an increase in the size of the opacity seen in the radiograph.

(c) A cold abscess may be the only presenting feature in an otherwise fit patient. These collections may have a cough impulse and usually present anteriorly, deep to the pectoral muscles, in the line of the incision, or in the axilla.

(d) The balls may migrate but uncommonly after the Cleland type of operation. Only one such case was found in this series:

A girl of 16 underwent right polythene plombage in January, 1951. She remained well until October, 1955, when she noticed a hard, tender lump in the axilla. This was thought to be an axillary adenitis, and, when incised as such, several ounces of pus and a polythene ball were found in the subcutaneous tissues. She was later referred for removal of the plombage and thoracoplasty.

(e) If the early signs of fluid are not detected the pus may rupture into the lung. This process may be relatively silent, and, in seven of the eight patients who developed a fistula, there was radiographic evidence of the leak weeks and, in one, months before the clinical diagnosis was made. There is always some malaise and a productive cough. The sputum usually contains tubercle bacilli. There is a characteristic radiographic appearance, the balls being outlined by crescents of air which has escaped from the lung. This escape of air may be limited by adhesions to a small area, giving the appearance of a cavity reopening beneath the plomb or a migrating sphere. A fistula may result from erosion of a large cavity into the space. This complication is due to faulty selection of cases, large cavities being particularly unsuitable for this type of collapse therapy.

A man of 26 who had a large cavity at the left apex, an unexpandable right lung, and a poor respiratory reserve underwent left plombage in 1952. Twelve months later erosion of the cavity into the plombage space necessitated resection of the left upper lobe and removal of the plomb. After this second operation the bronchial stump broke down and the patient died.

\section{Surgical Treatment}

The aim of treatment is to remove the foreign body, obliterate the space by thoracoplasty, and to resect the underlying lobe if it is actively diseased. This is the ideal and can only be achieved if the patient is in reasonably good general condition and has sufficient respiratory reserve to withstand such an extensive procedure. Operations should be done under cover of antituberculosis drugs, and if possible, pre-operatively, the space should be aspirated on several occasions and streptomycin instilled.

It is convenient to divide the surgical management into the following groups.

UnComplicated Tuberculous SPace INFECTION.-If the collapse has been maintained for at least two years, and there is a repeatedly negative sputum and there is no evidence of active disease on tomography and bronchography, all that is required is the removal of the pack and conversion to a formal thoracoplasty. When the space is opened it may be found that all the balls are lying loose in pus or, alternatively, some are walled off and a few are infected. All balls should be removed and a search made for any that may be lying hidden beneath a capsule of fibrous tissue. A sufficient number of ribs should be excised to permit embedding of the scapula. It is important to remove the first rib, although this may present

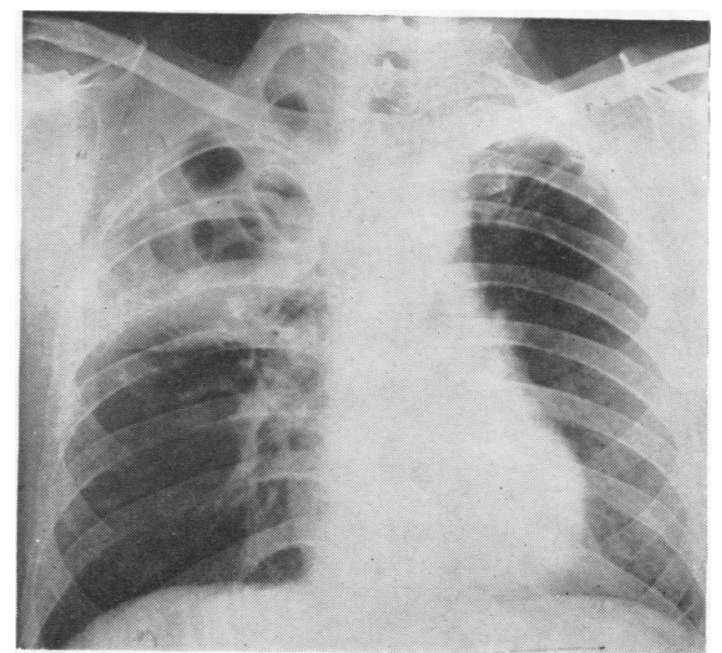

FIG. 1.-Radiograph of S.D. after right plombage with hollow spheres in 1950 . 


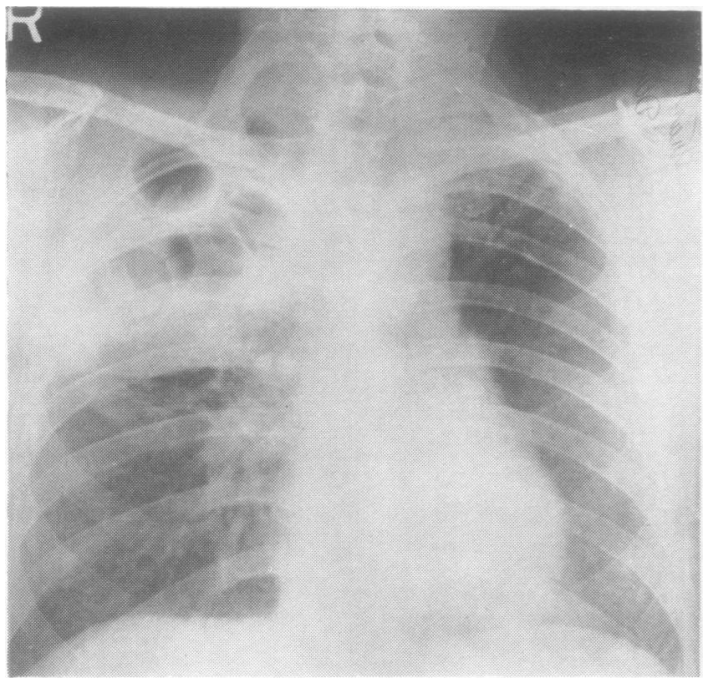

FIG. 2.-S.D. is now (1952) clinically well, but the radiograph shows fracture of the ribs overlying the plombage.

technical difficulty. All fibrin masses and granulations should be excised or curetted away, care being taken over the floor of the space which may be closely adherent to the underlying lung. The chest is closed with temporary drainage. Post-operatively the space is aspirated daily and $1 \mathrm{~g}$. of streptomycin instilled for as long as fluid can be obtained, usually for about one week or 10 days. The patient can be mobilized early and discharged within about six weeks without convalescence in a sanatorium.

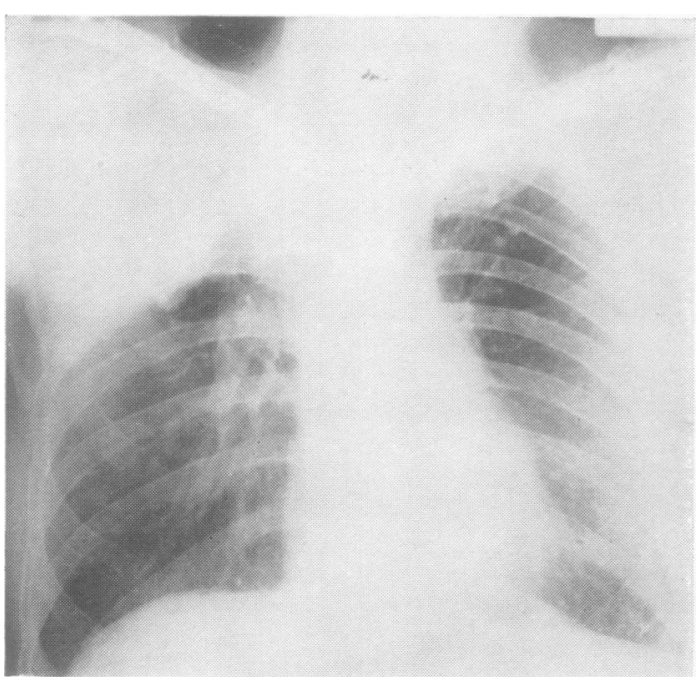

Fig. 4.-Radiograph of S.D. in 1956, two years after removal of the plomb and a right upper lobectomy and thoracoplasty.

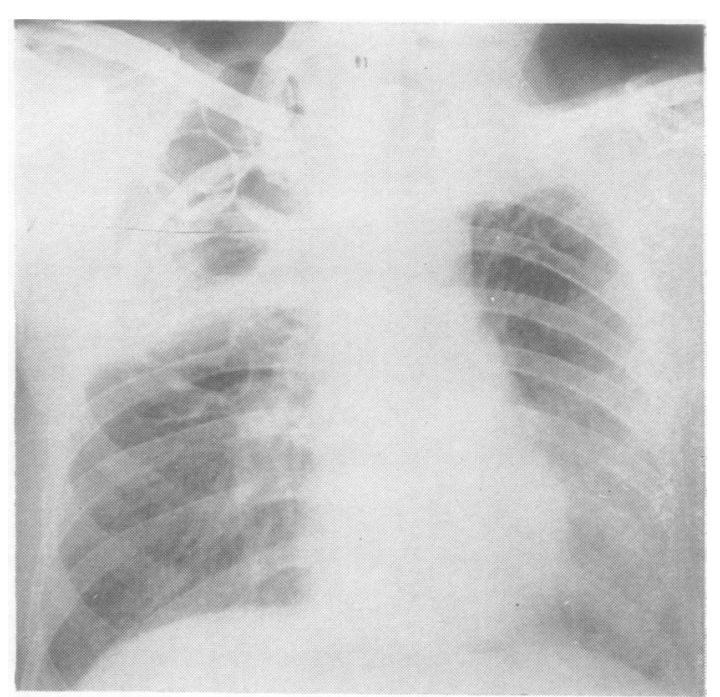

FIG. 3.-Radiograph of S.D. in 1954. Fluid has eroded into lung, and the radiograph shows crescents of air around the spheres.

SPaCe Infection Complicated by Bronchial Fistula.-If there has been no secondary infection and the patient is in good general condition it should be possible to carry out resection of the underlying lobe, removal of the plombage, and thoracoplasty in one stage. Occasionally, in the less fit patient, it may be necessary to postpone the thoracoplasty for two to three weeks after the lobectomy. Access to the lobe is facilitated by removing the balls before dealing with the lung. On no account should an attempt be made to deal

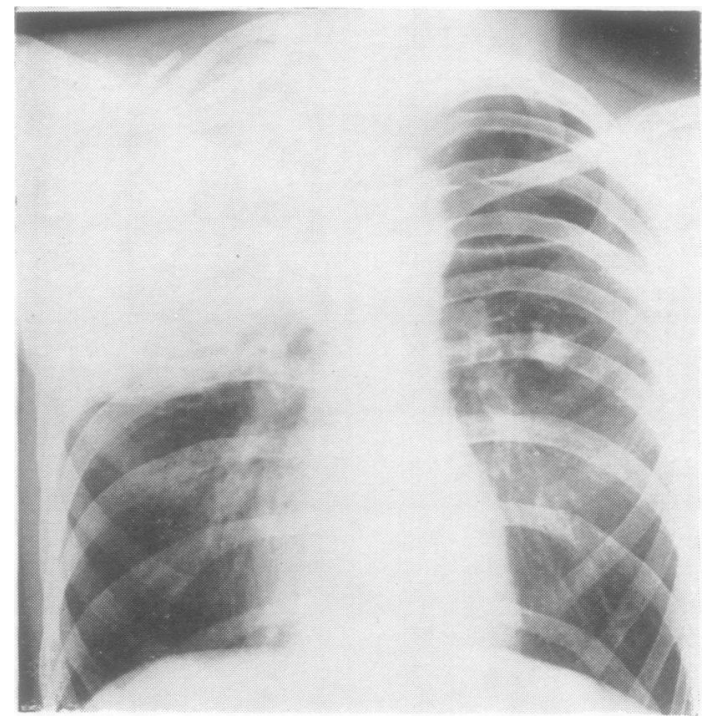

FIG. 5.-Radiograph of A.D. after right plombage in 1952. 


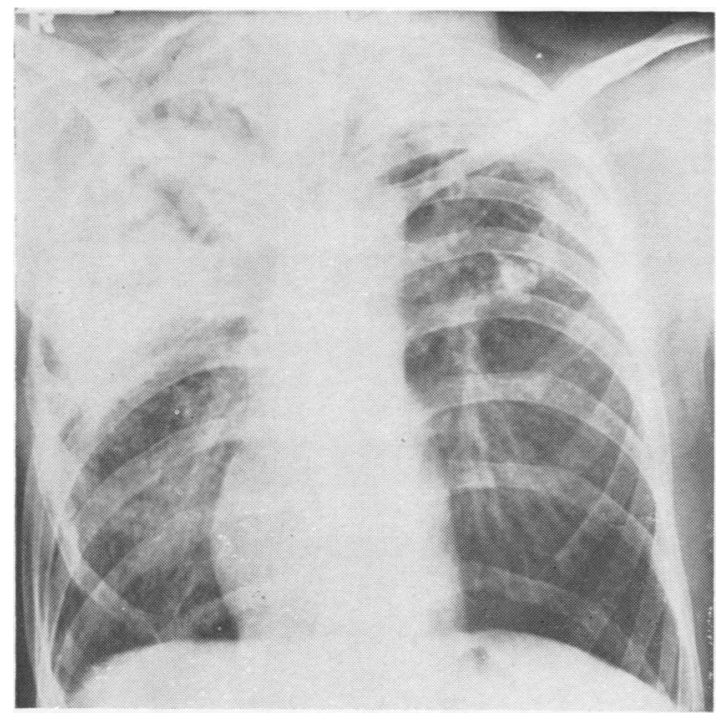

FIG. 6.-Radiograph of A.D. in 1956, showing bronchial fistula, space infection, and bronchopneumonia.

with this complication by merely removing the plomb and suture of the fistula through the floor of the space. Such a repair carried out in the presence of active tuberculous infection is doomed to failure.

Fistula Complicated by Secondary Infection AND BRONCHOPNEUMONIA.- - These patients are

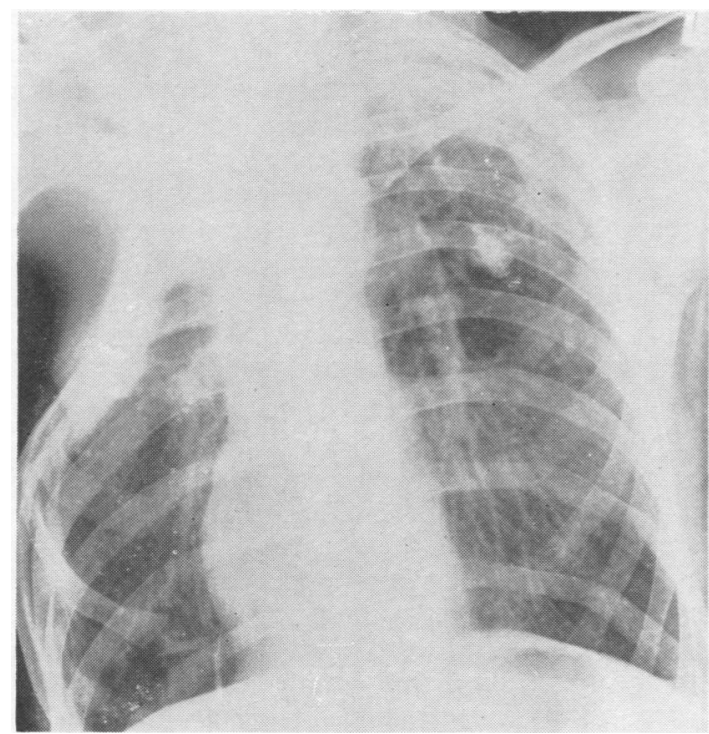

FIG. 8.-Radiograph of A.D. following closure of the space by thoracoplasty and decortication in July, 1957.

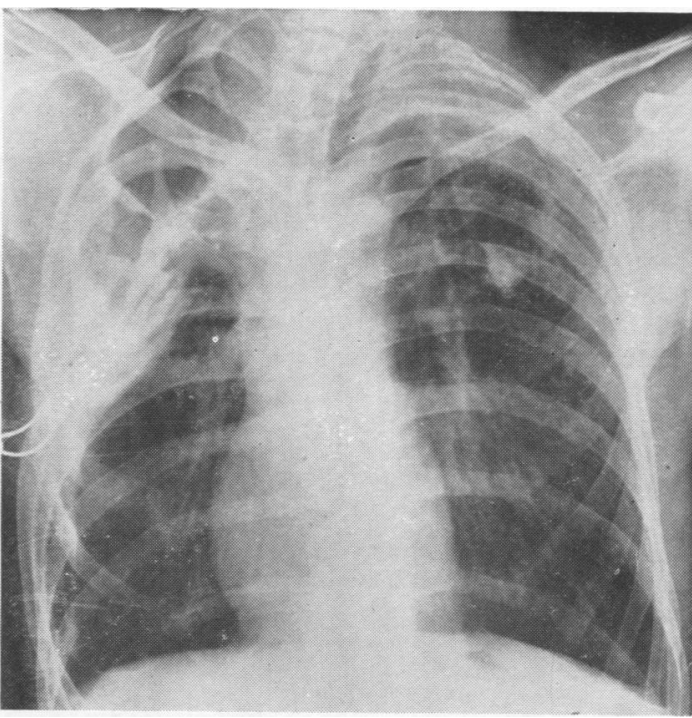

FIG. 7.-Radiograph of A.D. after drainage of the space and removal of the balls in May, 1956.

usually desperately ill and may die before much can be done to help them. If possible, as a first stage under local anaesthesia, the balls should be removed through a small incision and dependent drainage instituted. The patient will be left with a tube draining a large, secondarily infected tuberculous space with rigid bony walls and communi-

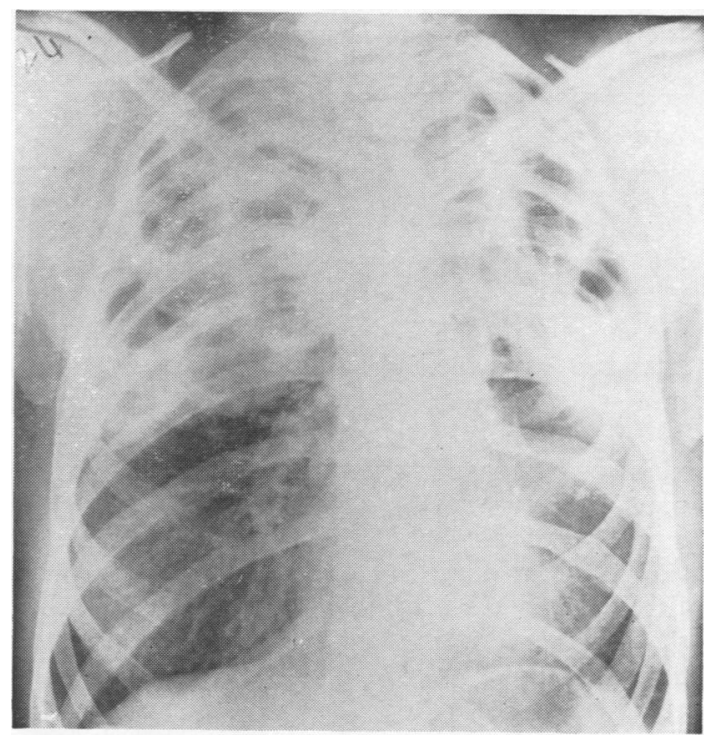

FIG. 9.-Radiograph to show bronchial fistula mimicking a cavity reopening beneath the left plombage. 
cating with the lung by small fistulae. The closure of such a space presents a formidable problem.

A man of 32 who had bilateral disease underwent right plombage in 1952. This failed to close the cavity and in 1954 a right upper lobectomy was carried out. He remained well until 1956, when he developed a space infection, fistula, secondary infection, and bronchopneumonia. The situation was dealt with as outlined above and the whole space closed some months later as a result of a combination of thoracoplasty and decortication.

\section{RESUltS}

Of the 22 cases in the series, 14 were of the "simple" type and eight had a bronchial fistula as well. Tubercle bacilli were found in the liquid from the plomb space in 21 cases. The exception was in one man in whom the diagnosis was made at necropsy ; characteristic appearances of a space infection were found, but no bacteriological examination was made. In 11 out of 12 cases where the investigation was done, there was an increase in the erythrocyte sedimentation date.

SUMMARY OF CASES

\begin{tabular}{rr|c|c|c|c}
\hline \multicolumn{1}{c|}{ Type } & No. & Deaths & $\begin{array}{c}\text { Alive and } \\
\text { Well }\end{array}$ & $\begin{array}{c}\text { Still under } \\
\text { Treatment }\end{array}$ \\
\hline "Simple". &. & 14 & 1 & 13 & 0 \\
With fistula &.. & 8 & 3 & 3 & 2 \\
\hline Totals &.. & 22 & 4 & 16 & 2 \\
\hline
\end{tabular}

TIME ELAPSING BETWEEN ORIGINAL PLOMBAGE AND DIAGNOSIS OF SPACE INFECTION

\begin{tabular}{l|c|c|c|c|c|c}
\hline Period .. & $6 / 12$ & 1 Year & 2 Years & 3 Years & 4 Years & 5 Years \\
\hline No. of cases & 1 & 1 & 3 & 7 & 7 & 3 \\
\hline
\end{tabular}

Thirteen of the 14 "simple" cases were treated by thoracoplasty after removal of the balls and all the patients are well and sputum negative at the time of follow-up. Troublesome sinuses occurred in two of these patients, but these ultimately closed and have remained healed. The one death in the "simple" group occurred in a man who was admitted moribund as a case of bronchopneumonia and died before anything could be done. The diagnosis of a space infection was made at necropsy.

In contrast with the relatively benign simple space infection, the appearance of a bronchial fistula increases the hazards to the patient. In eight such cases there were three deaths, one following lobectomy as described earlier, one following an attempt to suture the fistula, and one of bronchopneumonia in spite of drainage of the space. Of the five survivors, three were treated by lobectomy, removal of plombage, and thoracoplasty; these are all well and sputum negative. The two others were patients in whom a bronchial fistula was undiagnosed until the onset of bronchopneumonia. One is a patient who is awaiting further surgery after preliminary drainage, the other has had the space and fistula closed by decortication and thoracoplasty after a period of simple drainage. With the exception of two recent cases the follow-up covers a period of between one and five years. A simple space infection can be innocuous; all treated cases are alive and well. The additional factor of a bronchial fistula is a grave complication, particularly if its early diagnosis is missed.

\section{Discussion}

With the rising incidence of space infection which is to be expected in the future, the indications for plombage must be limited. It is probable that the operation should only be used in those patients who are unfit for other forms of surgery by reason of reduced respiratory reserve. In view of this increasing hazard, consideration should be given to the question whether established plombages, after a period of, say, three years, should be "abandoned" and converted to a small thoracoplasty - a procedure analogous to that occasionally used with the extrapleural pneumothorax. Certainly, in cases where resection is carried out under a plombage the plastic material should be removed at the same time, lest it should give rise to trouble in the future, however tempting it may be to leave such a convenient space-filling mass. In four of the cases reported here, balls not removed at the time of a secondary lobectomy gave rise to trouble later. This tends to confirm the view expressed by Desforges and others (1954) that in some cases the source of the infection is the extrafascial lymphatics and not the underlying lung.

Patients with a plombage are always at risk and the possibility of a latent space infection should be in the mind of those responsible for their aftercare. Warning signs are the onset of discomfort at the site of operation, malaise, unexplained fever, an increase in the erythrocyte sedimentation rate, or the appearance of a swelling. Routine radiographs should be examined critically for evidence of any increase in size of the opacity, for gross thinning or fracture of the ribs, and for the presence of air in the space. 
Treatment of a simple space infection is straightforward and satisfactory. The development of a fistula increases the hazard to the patient and complicates his treatment, but the neglected case with secondary infection and bronchopneumonia will often die.

\section{SUMMARY}

Twenty-two cases of late tuberculous space infection after plombage, with discussion of the clinical types, their diagnosis, and treatment, are cited. Thirteen of 14 cases of "simple" infections are alive and well after conversion to thoracoplasty, whereas in eight cases complicated by bronchial fistula there were three deaths and three survivors who are well and with a negative sputum.

\section{REFERENCES}

Cleland, W. P. (1956). J. thorac. Surg., 32, 813.

Desforges, G., Gibbons, G., and Strieder, J. W. (1954). Ibid., 28, 636. Inada, K., Satô, A., Kishimotô, S., and Tanabe, G. (1954). Ibid., $27,503$.

Jackson, C. A., and McCann, J. J. (1956). Tubercle (Lond.), 37, 36. Lucas, B. G. B., and Cleland, W. P. (1950). Thorax, 5, 248.

McIndoe, R. B., Steele, J. D., Jr., and Alexander, J. (1939). Amer. Rev. Tuberc., 40, 243.

Trent, J. C., Moody, J. D., and Hiatt, J. S., Jr. (1949). J. thorac. Surg., 18, 173.

Wilson, D. A. (1948). Ibid., 17, 111. 